\title{
MODELING AND ANALYSIS OF A SEA WAVE ENERGY CONVERTER
}

\author{
Isaac R. Machado ${ }^{1}$, Edson H. Watanabe ${ }^{2}$ and Paula B. Garcia-Rosa ${ }^{3}$ \\ ${ }^{1}$ Federal University of Ceará - UFC, Sobral - CE, Brazil \\ ${ }^{2}$ Federal University of Rio de Janeiro, COPPE/UFRJ, Rio de Janeiro - RJ, Brazil \\ ${ }^{3}$ Centre for Ocean Energy Research, Maynooth University, Maynooth, Ireland \\ e-mail: isaacmachado@gmail.com, watanabe@coe.ufrj.br, paula.garciarosa@eeng.nuim.ie
}

\begin{abstract}
This paper presents the analysis and optimization of a wave-to-wire energy converter developed by COPPE / UFRJ researchers. The main features of this technology are: the use of a Hydropneumatic Storage System (HSS) to filter the wave power oscillations absorbed and a Double Feed Induction Generator (DFIG) to perform electromechanical energy conversion. Mathematical models for all conversion stages (from the waves to the electrical grid) are shown and the integrated control strategy of electromechanical and hydropneumatic systems is proposed to maximize the utilization of Wave Energy Converter $(W E C)$. Simulation results (MATLAB/SIMULINK) are presented to evaluate the performance of energy storage systems (compression air and rotating masses inertia) and their impact on the power quality.
\end{abstract}

Keywords - waves; hydropneumatic accumulator ; hydraulic pressure ; DFIG.

\section{INTRODUCTION}

The Wave Energy Converter (WEC) developed by COPPE / UFRJ researchers is based on water pumping performed by waves action on floating body. A Hydropneumatic Storage System $(H S S)$ associated with a Pelton hydraulic turbine and electric generator are used. The operating principle is based on the floating body movements by the wave action, which through mechanical arms drives a hydraulic pump. The hydraulic pumps, inject water in a high pressure $H S S$, thus, the intermittent energy extracted from the waves is stored. A valve fixed to the $H S S$ controls a waterjet with pressure and flow sufficient to drive a Pelton turbine. Fig. 1 shows the proposed topology.

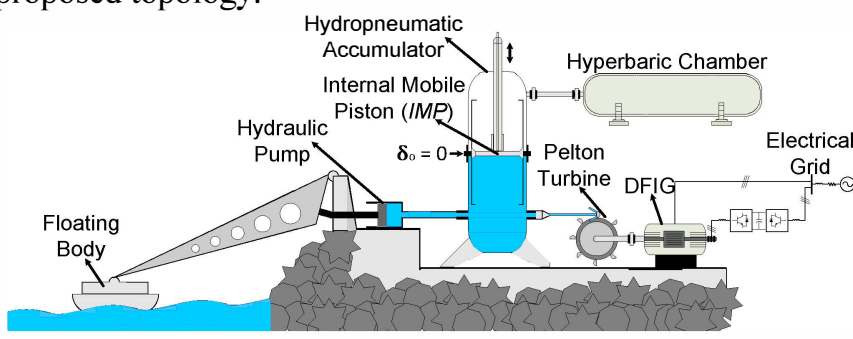

Fig. 1. Wave energy converter topology.

The HSS consists of a hydropneumatic accumulator connected to a hyperbaric chamber. The inside of the hydropneumatic accumulator consists of air and water, separated by a Internal Mobile Piston (IMP) which moves freely in the course of a few meters. Thus, when the input water flow (water pumped by the floating body action) is greater than the output water flow (water flow that drives the hydraulic turbine through control valve), the piston rises storing the wave energy in the compressed air. In dual form, when the output water flow is greater than the input water flow, the piston moves down (expansion of the air) releasing the wave energy stored. A protection system against excessive high pressures consists in a set of relief valves that act when the internal pressure exceeds the maximum limit established in the structural design. The fresh water used in the hydraulic system circulates in a closed cycle. A restitution reservoir accumulates the water used to drive the turbine that is reused by the pumping modules.

A wide variety of $W E C$ topologies is being investigated by research institutions around the world. Many published papers have discussions about power quality, control interfaces and power electronics in grid connected WEC topologies. POLINDER \& SCUOTTO (2005) [1] presented the main power system impacts of the typical WEC topologies. A common feature of all WEC topologies is the intermittent power generated (power oscillations typically around 0,1 to 0,2 Hz). MOLINAS et al. (2007) [2] presented a comparative study of a WEC using different grid connected generators types: directly connected Squirrel Cage Induction Generator $(S C I G)$, $S C I G$ with a full power back-to-back converter and DFIG. HANSEN et. al. (2011) [3] discussed the Maximum Power point Tracking (MPPT) that utilizes multiple hydraulic systems in parallel, each with a determined operation pressure. With the use of a valves system the water flow is directed to a specific hydraulic system (with defined hydraulic operating pressure). Consequently, discrete changes in the hydraulic pressure operation is obtained. The goal is to keep the floating body position in resonance with the incident wave. KIPRAKIS et. al. (2009) [4] presented an analysis of the influence of the size and number of floats in the wave generation farm efficiency. The spacing and positioning of the floats relative to the incident wave front are the main analysis points. GERCES et. al. (2010) [5] have shown an alternative configuration using linear generators directly connected to the floating bodies, i.e., without HSS. This topology comprises in a Voltage Source Converter (VSC) with Pulse Width Modulation $(P W M)$ control installed on each float-generator module, rectifying and injecting the active power generated in a common $D C$ bus. Single VSC with $P W M$ control is used to connect the farm on the grid.

In the case of the WEC developed by COPPE / UFRJ, some studies have been developed. GARCIA-ROSA (2008) [6] presented in his dissertation the MPPT criterion for the waves and floating body interaction. Classical MPPT techniques (reactive and latching controls) were presented and simulated. GARCIA-ROSA et. al. (2010) [7] - [8] presented the complete modeling of $W E C$ (wave to wire model). This study analyzed 
the influences of hydraulic pressure levels, water flow and hydraulic volume on the power quality. A synchronous generator was used in isolated and connected study cases. MACHADO et. al. (2011) [9] studied the influence of HSS capacity in the power quality generated. The topology that uses a grid connected DFIG. MARTINEZ. et. al. (2011) [10] - [11] analyzed a topology with permanent magnet synchronous generator and multi-level back-to-back converter applied to distributed generation. GARCIA-ROSA (2013) [12] detailed the dynamic modeling, but using a synchronous generator. Simulation results showed that the control of the HSS internal pressure is essential for the MPPT floating body operation. Thus, it is necessary that the hydraulic pressure is monitored and adjusted continuously according to the changes of the sea state.

In this context, this work presents a proposal for an integrated control between the HSS and the DFIG in order to maximize the extraction of wave energy. Therefore, the IMP position control (see in Fig. 1) associated with DFIG speed control are implemented [13]. All modeling and control strategies are detailed and the simulation results using MATLAB / SIMULINK software are presented and discussed.

\section{MODELING}

\section{A. Sea State}

The main elements of a regular and monochromatic wave (sinusoidal and fixed frequency) are shown in Fig. 2. It is defined as wavelength $(\lambda)$ the distance between two successive crests, wave amplitude $(A)$ the distance between the crest and the reference level zero, wave height $(H)$ distance between a crest and a valley and period $(T)$ the time interval between two successive crests.

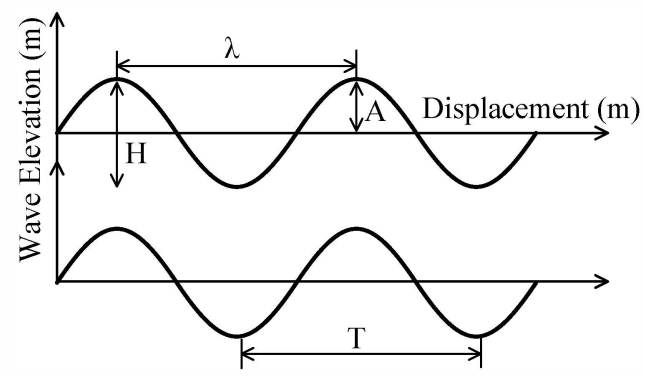

Fig. 2. Main elements of a regular Wave.

In real seas modeling is made by a superposition of different monochromatic components at various frequencies. A "sea state" is characterized by two statistical parameters: the significant wave height $\left(H_{s}\right)$ and the average period $\left(T_{\alpha v}\right)$. The significant wave height is defined as the arithmetic average of the third (1/3) of the biggest waves observed and average period is the arithmetic mean of the observed periods [14].

A particular sea state has duration of approximately 3 to 4 hours and $H_{s}$ and $T_{c v}$ parameters remain almost constant being used to determine the spectral energy density. Here, thet Bretschneider spectrum presented by PARSONS \& BADDOUR [15] was used. In this model, the spectral energy density at a given wave frequency $\omega$, in $\mathrm{m}^{2} \mathrm{~s}$, is given by:

$$
S_{n}(\omega)=\frac{A_{w}}{\omega^{5}} \exp \left(\frac{-B_{w}}{\omega^{4}}\right),
$$

where:

$$
A_{w}=172,5 \frac{H_{s}^{2}}{T_{a v}^{4}} \text { and } B_{w}=\frac{691}{T_{a v}^{4}} .
$$

PÉREZ et. al. [16] constitute a time series which determines the wave elevation employing the expression:

$$
A(t)=\sum_{i=1}^{n} A_{i} \cos \left(\omega_{i} t+\varphi_{i}\right),
$$

where $A_{i}$ is the amplitude of the i-th term of the wave, $\omega_{i}$ is the angular frequency of the i-th term of the wave and $\varphi_{i}$ a random phase of $\mathrm{i}$-th term. The amplitude of the $\mathrm{i}$-th term is calculated using the expression:

$$
A_{i}=0,5\left[\frac{\mathrm{S}\left(\omega_{\mathrm{i}}\right) \omega_{\mathrm{i}}}{\pi}\right]^{1 / 2}
$$

\section{B. Float and Hydraulic Pump}

The operation of the float-pump group is given in two stages: (a) the pump compression stage (when a water volume is injected into the HSS) occurs in the downward float movement and (b) the admission pump stage (when pump fills water again) occurs in the upward float movement. In this moment, the pressure on the piston is substantially equal to atmospheric pressure. Fig. 3 shows the simplified model and the equivalent model presented by GREENHOW \& WHITE [16] and CUMMIS [17].

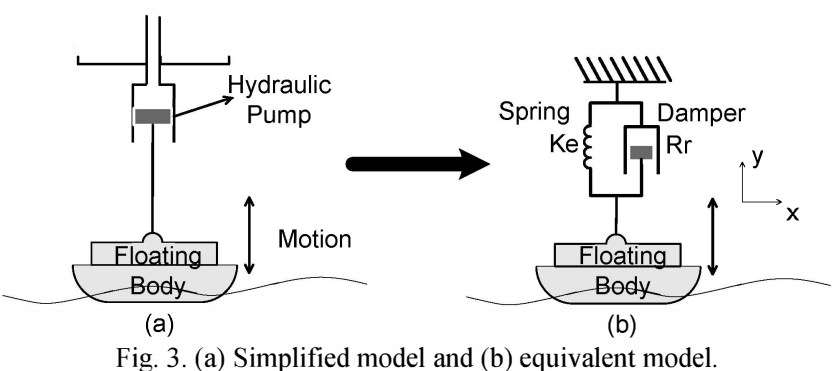

The equation that determines the floating body movement associated with the action of the waves is given by:

$$
M \ddot{y}(t)+R_{r} \dot{y}(t)+K_{e} y(t)=F_{e}+F_{p},
$$

where $M$ is the floating body mass $(\mathrm{kg}), R_{r}$ is the potential damping coefficient or radiation coefficient $(\mathrm{kg} / \mathrm{s})$ and $K_{e}$ is the elasticity coefficient of the floating body $(\mathrm{N} / \mathrm{m})$. The external forces applied to the floating body are: the wave force $\left(F_{e}\right)$ and the hydraulic pump piston reaction force $\left(F_{p}\right)$. Due to the oscillatory movement of the floating body, there is a wave radiating on the free surface of the sea. These waves are radiated away from the float, but still continue to affect its movement in subsequent moments due to the interaction with the incident waves. The modeling of this phenomenon provides an increase of mass to the oscillating body called additional mass $\left(M_{r}\right)$, and (5) becomes:

$$
\left(M+M_{r}\right) \dot{y}(t)+R_{r} \dot{y}(t)+K_{e} y(t)=F_{e}+F_{p} .
$$

The excitation force $\left(F_{e}\right)$ applied to an oscillating body due to the action of a sine wave is given by [14]:

$$
F_{e}(t)=F_{e_{-} \max } \cos (\omega t),
$$

where: 


$$
F_{e_{-} \max }=\left(\frac{2 \rho g^{2} A^{2} R_{r}}{\omega k}\right)^{1 / 2} .
$$

In (8), $\rho$ is the water density $\left(\mathrm{kg} / \mathrm{m}^{3}\right), g$ the gravity acceleration $\left(\mathrm{m} / \mathrm{s}^{2}\right)$ and $k$ (defined by $\left.2 \pi / \lambda\right)$ the wave number $(\mathrm{rad} / \mathrm{m})$. In real seas, the excitation force is calculated as the sum of various monochromatic components:

$$
F_{e}(t)=\sum_{i=1}^{n} F_{e_{-} i}(t)=\sum_{i=1}^{n}\left(\frac{2 \rho g^{2} A_{i}^{2} R_{r}}{\omega_{i} k_{i}}\right)^{1 / 2} \cos \left(\omega_{i} t+\varphi_{i}\right) .
$$

The force that the hydraulic pump piston exerts on the float $\left(F_{p}\right)$ is given by:

$$
F_{p}=\left\{\begin{array}{ll}
A_{1} P_{1}, & \dot{y} \geq 0 \\
0, & \dot{y}<0
\end{array},\right.
$$

where $A_{l}$ is the cross-sectional area of the hydraulic pump and the $P_{I}$ is the hydraulic pressure of the HSS. Finally, the input water flow on the $H S S$ is given by:

$$
Q_{i n}(t)=\left\{\begin{array}{l}
A_{1} \dot{y}(t), \dot{y} \geq 0 \\
0, \quad \dot{y}<0
\end{array} .\right.
$$

\section{Hydraulic Storage System (HSS)}

Fig. 4 shows the HSS topology (without hyperbaric chamber) and the model variables. The hyperbaric chamber is not shown, but its function is to act as a "lung" giving an additional air pressurized volume to the system. The modeling is based on Bernoulli's equation for incompressible liquids. Several examples of hydraulic modeling are presented by LIVI [18]. Applying the Bernoulli's equation to the points 1 and 2 shown in Figure 4:

$$
P_{1}+\frac{1}{2} \rho V_{1}^{2}+\rho g h_{1}=P_{2}+\frac{1}{2} \rho V_{2}^{2}+\rho g h_{2},
$$

where the variables $P, V$ and $h$ represent pressures, waterjet speeds and water height levels, respectively. Whereas points 1 and 2 are at the same height reference $\left(h_{1}=h_{2}\right)$, the waterjet speed on the HSS output is given by:

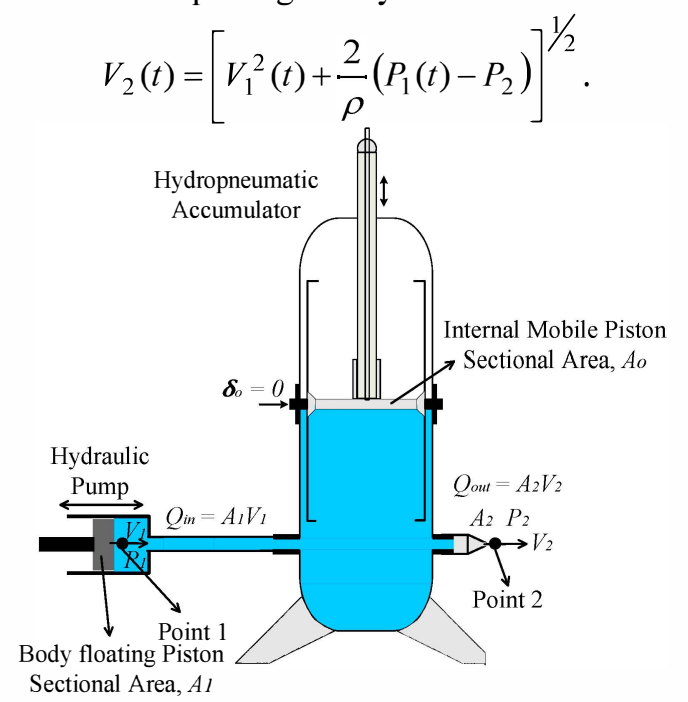

Sectional Area, $A l$

Fig. 4. HSS topology (without hyperbaric chamber) and modelling variables.
The pressure at point $2\left(P_{2}\right)$ is the atmospheric pressure $(1 \mathrm{~atm}$ or $10^{5} \mathrm{~N} / \mathrm{m}^{2}$ ) and the $H S S$ internal pressure, $P_{I}(t)$, is a function of IMP position, $\delta(t)$. Whereas isothermal compressions and expansions of the chamber gas, $P_{l}(t)$ is obtained through the ideal gases expression, given by:

$$
P_{1}(t)=\frac{P_{o} V_{L o}}{V_{L 1}(t)}=\frac{P_{o} V_{L o}}{V_{L o}-\delta(t) A_{O}},
$$

where $P_{o}$ and $V_{L o}$ represents the initial hydraulic pressure and initial chamber gas volume, respectively. $P_{I}$ and $V_{L I}$ represents the pressure and gas volume after compression (or expansion), respectively. Substituting (14) into (13):

$$
V_{2}(t)=\left[V_{1}^{2}(t)+\frac{2}{\rho}\left(\frac{P_{o} V_{L o}}{V_{L o}-\delta(t) A_{o}}-P_{2}\right)\right]^{1 / 2} .
$$

It's observed that the waterjet speed $V_{2}$ is a function of the $\delta$ $I M P$ position and the $V_{1}$ speed. In practice, $V_{2}$ is much larger than $V_{l}$, hence the HSS output waterjet speed is influenced mainly by the internal IMP position, $\delta$. Soon it is clear that controlling the IMP position $\delta$, indirect control of $P_{1}$ and $V_{2}$ is obtained.

The $\delta$ position is obtained from difference between the output and input $H S S$ water volumes. Considering the volumes as the integral of the water flows:

$$
\delta(t)=\frac{1}{A_{o}} \int Q_{\text {in }}(t) d t-\frac{1}{A_{o}} \int Q_{\text {out }}(t) d t+\delta_{o},
$$

where $Q_{i n}, Q_{\text {out }}$ and $\delta_{o}$ are the input water flow, output water flow and initial IMP position, respectively. Considering that $Q_{\text {out }}$ can be calculated from the $V_{2}$ by $A_{2}$ (cross-sectional area of the $H S S$ output water jet) product, (16) becomes:

$$
\delta(t)=\frac{1}{A_{o}} \int Q_{i n}(t) d t-\frac{A_{2}}{A_{o}} \int V_{2}(t) d t+\delta_{o} .
$$

\section{Pelton Turbine}

Fig. 6 shows the Pelton turbine topology. It comprises a wheel with several blades cupped. The incident water jet (from the HSS), collide with the blades causing a mechanical torque and the turbine speed up. According LIVI [18], the expression that calculates the mechanical torque can be developed using a dotted red Contour Volume $(C V)$ that involves a blade as detailed in Fig. 5.

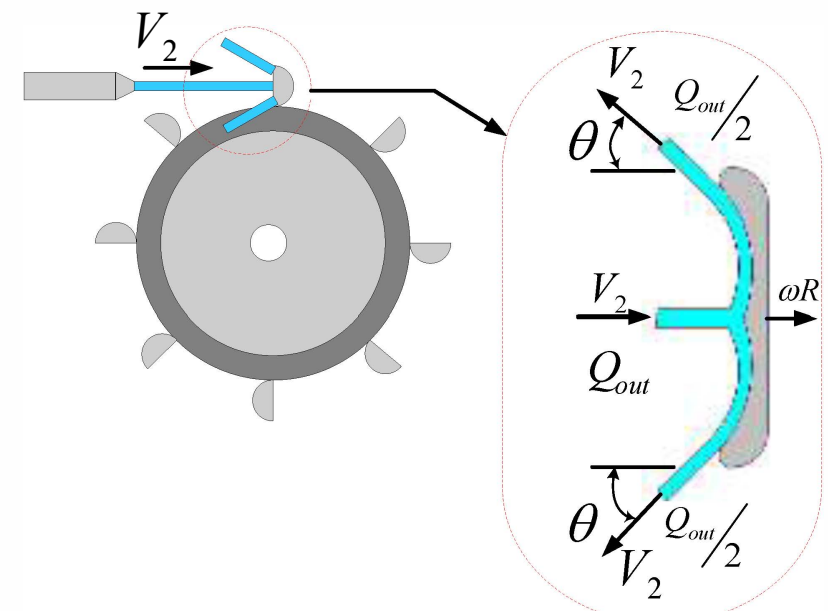

Fig. 5. Pelton turbine and modelling variables. 
Therefore, from the sum of the angular momentum entering and leaving the volume contour, there are obtained:

$$
T_{m}=(\text { Angular momentum flow entering the } C V)+
$$$$
+(\text { Angular momentum flow exting the } C V)
$$

Considering the water jets directions shown in Fig. 5, (18) becomes:

$T_{m}=R_{t}\left(V_{2}-\omega_{m} R_{t}\right) \rho Q_{\text {out }}+R_{t}\left(V_{2}-\omega_{m} R_{t}\right) \cos \theta \rho\left(-Q_{\text {out }} / 2\right)+$

$+R_{t}\left(V_{2}-\omega_{m} R_{t}\right) \cos \theta \rho\left(-Q_{\text {out }} / 2\right)$.

Finally, regrouping similar terms:

$$
T_{m}=R_{t}\left(V_{2}-\omega_{m} R_{t}\right)(1-\cos \theta) \rho Q_{o u t} .
$$

The turbine mechanical power is given by the torque by speed product:

$$
P_{m}=R_{t} \omega_{m}\left(V_{2}-\omega_{m} R_{t}\right)(1-\cos \theta) \rho Q_{o u t} .
$$

It is noticed that $P_{m}$ is quadratic function of $\omega_{m}$ and the maximum value in (21) depends on the water jet speed $\left(V_{2}\right)$ and the turbine radius $\left(R_{t}\right)$. The optimal speed turbine to operate at maximum efficiency is given by:

$$
\omega_{r e f}=\frac{V_{2}}{2 R_{t}} \text {. }
$$

\section{E. $\quad$ DFIG}

This section presents the modeling of Wound Rotor Induction Machine in synchronous $d q$ reference frame as demonstrated by BOSE et. al. and KRAUSE et. al. [19], [20]. The differential equations that describe the voltages of the stator windings are:

$$
\begin{aligned}
& v_{s d}=R_{s} i_{s d}+\frac{d \psi_{s d}}{d t}-\omega_{s} \psi_{s q}, \\
& v_{s q}=R_{s} i_{s q}+\frac{d \psi_{s q}}{d t}+\omega_{s} \psi_{s d},
\end{aligned}
$$

where $v, R, i, \psi$ and $\omega_{s}$ represent voltages, resistances, currents, magnetic fluxes and angular frequency of the stator flux vector, respectively. In all equations the superscript " $s$ " and " $r$ " represent the magnitudes of stator and rotor, respectively. The superscript " $d$ " and " $q$ " refers to direct and quadrature axes, respectively. The stator flux direct and quadrature components are be expressed by:

$$
\begin{aligned}
& \psi_{s d}=L_{L s} i_{s d}+L_{m}\left(i_{s d}+i_{r d}\right), \\
& \psi_{s q}=L_{L s} i_{s q}+L_{m}\left(i_{s q}+i_{r q}\right),
\end{aligned}
$$

where $L_{L s}$ and $L_{m}$ are the stator leakage inductance and magnetization inductance, respectively.

Similarly, the differential equations of the rotor are:

$$
\begin{aligned}
& v_{r d}=R_{r} i_{r d}+\frac{d \psi_{r d}}{d t}-\omega_{s l} \psi_{r q}, \\
& v_{r q}=R_{r} i_{r q}+\frac{d \psi_{r q}}{d t}+\omega_{s l} \psi_{r d} .
\end{aligned}
$$

The direct and quadrature rotor flux in (27) and (28) are expressed by

$$
\begin{aligned}
& \psi_{r d}=L_{L r} i_{r d}+L_{m}\left(i_{s d}+i_{r d}\right), \\
& \psi_{r q}=L_{L r} i_{r q}+L_{m}\left(i_{s q}+i_{r q}\right),
\end{aligned}
$$

and the slip frequency is given by:

$$
\omega_{s l}=\omega_{s}-p \omega_{m},
$$

where $p$ is the number of pole pairs of the machine. Neglecting the mechanical friction, the modeling of the rotor dynamics is given by:

$$
T_{e}-T_{m}=J \frac{d \omega_{m}}{d t},
$$

where $T_{e}$ and $J$ are the electromagnetic torque and moment of inertia of the machine rotor, respectively.

The DFIG model used in the implemented simulations takes into account simplifications proposed by LIMA and WATANABE [21], [22]. In this simplified model, the intrinsic machine characteristics, such as lower stator resistance, field oriented control [23] and a fast synchronization system are considered. Here, it was considered that: (i) field oriented control is applied $\left(\psi_{s q}=0\right)$, (ii) the stator voltage vector is fully aligned on the $q$ axis $\left(v_{s d}=0\right)$ and (iii) neglecting the stator resistance. Then, applying Laplace transformation to (23), (24), (25) and (26), the stator currents become:

$$
\begin{gathered}
I_{s d}(s)=\frac{V_{s q}}{L_{s} \omega_{s}}-\frac{L_{m}}{L_{s}} I_{r d}(s), \\
I_{s q}(s)=-\frac{L_{m}}{L_{s}} I_{r q}(s) .
\end{gathered}
$$

The analysis of (33) and (34) shows that when the DFIG operates connected to a fixed voltage bar and the field oriented control is applied, the currents of the rotor and stator are directly proportional and the generator has current source characteristics [21], [22].

The electromagnetic torque of the machine is given by:

$$
T_{e}=p\left(\psi_{s q} i_{s d}-\psi_{s d} i_{s q}\right) .
$$

Whereas the field oriented control is applied $\left(\psi_{\text {sq }}=0\right)$, applying the Laplace transform and substituting (34) into (35), we obtain:

$$
T_{e}(s)=p \frac{L_{m}}{L_{s}} \Psi_{s d} I_{r q}(s) .
$$

Maintaining the machine magnetization $\left(\Psi_{s d}\right)$ constant, the electromagnetic torque $\left(T_{e}\right)$ can be adjusted through quadrature rotor current control $\left(I_{r q}\right)$.

The stator active power is given by:

$$
P_{s}=v_{s d} i_{s d}+v_{s q} i_{s q} \text {. }
$$

Considering that field oriented control is applied $\left(v_{s d}=0\right)$, applying the Laplace transform and substituting (34) into (37):

$$
P_{s}(s)=-\frac{L_{m}}{L_{s}} V_{s q} I_{r q}(s) .
$$

The stator reactive power is given by:

$$
Q_{s}=v_{s d} i_{s q}-v_{s q} i_{s d} .
$$

Similarly to active power case and substituting (33) into (39) the stator reactive power is given by:

$$
Q_{s}(s)=-\frac{V_{s q}^{2}}{\omega_{s} L_{s}}+\frac{L_{m}}{L_{s}} V_{s q} I_{r d}(s) .
$$

The analysis of (40) shows that it is possible to adjust the stator reactive power $\left(Q_{s}\right)$ by controlling the direct-axis rotor 
current $\left(I_{r d}\right)$. The first part of (40) is the reactive power necessary for the magnetization of the induction machine. The magnetization of the $D F I G$ can be made by the stator or the rotor.

\section{CONTROL STRATEGY}

The control strategy was evaluated with the WEC connected to $380 \mathrm{~V}$ electrical grid, short-circuit ratio of 20 and $R / X_{L}$ ratio equal to 4 . The magnetization of the $D F I G$ was taken by the rotor. Thus, only active power will flows in the stator circuit $\left(i_{s d}=0\right)$ and the Power Factor $(P F)$ is unitary in the Point of Common Coupling (PCC).

The HSS control is based on a control loop that acts to regulate the waterjet area $\left(A_{2}\right)$ that drives the turbine. The feedback parameter is the IMP position $(\delta)$, which should be controlled at a constant average position equal to the $\delta_{\text {ref }}$. Logically it would be impractical to control the absolute IMP position in a fixed value because the $H S S$ would lose its main function (filtering the oscillating power) and all intermittent wave power would be transferred to the grid. In fact it is desirable for the IMP move around the average position, being free to oscillate within certain limits. These oscillations enable filtering of the oscillating wave power absorbed. Thus, only the average $\delta$ position must be controlled. A low-pass filter is included for filtering the error $\boldsymbol{\varepsilon}$ ( $\boldsymbol{\varepsilon}_{\text {filt }}$ is the average of $\boldsymbol{\varepsilon}$ in 12 seconds, or two wave periods) and $\boldsymbol{\varepsilon}_{\text {filt }}$ is the Proportional Integrator $(P I)$ controller input parameter. The $\delta$ parameter could also be filtered directly, but this option was ruled out due to the inclusion of a zero in the feedback loop transfer function. The inclusion of the zero would cause high overshoots in the $\delta$ position (hence in $P_{1}$ and $V_{2}$ ) when the system is subjected to changes in the reference value $\left(\delta_{\text {ref }}\right)$. The output of the PI controller is the waterjet area $\left(A_{2}\right)$ to be adjusted.

Fig. 6 shows the proposed control scheme. The HSS control described is associated with the DFIG speed control. Thus $\omega_{m}$ speed is adjusted in order to maintain the Pelton turbine in the maximum efficiency, according to (22). Assuming that the $H S S$ control loop functioning properly, the $\delta_{\text {ref }}$ parameter is used to estimate $V_{2}$ waterjet speed (Eq. (15) using $V_{1}=0$ ). Finally the speed reference $\omega_{\text {ref }}$ is calculated using (15).

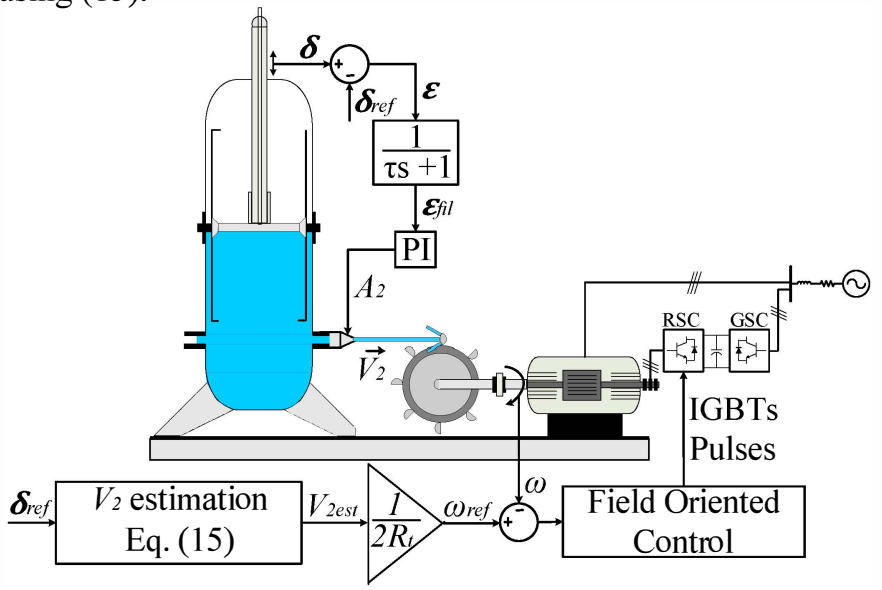

Fig. 6. HSS and DFIG integrated control.

\section{SimUlation RESUlTS}

Three floats-pump modules were considered. Each module injects water into common HSS. The simulation parameters are presented in Table 1.

TABLE I. Simulated Parameters

\begin{tabular}{|c|c|c|}
\hline Parameter & Description & Value \\
\hline \multicolumn{3}{|c|}{ Float } \\
\hline $\boldsymbol{K}_{e}$ & Elasticity coefficient & $32587 \mathrm{~N} / \mathrm{m}$ \\
\hline$M$ & Mass & $17000 \mathrm{~kg}$ \\
\hline$M_{r}$ & Additional mass & $12716 \mathrm{~kg}$ \\
\hline $\boldsymbol{R}_{r}$ & Radiation coefficient & $5379 \mathrm{~kg} / \mathrm{s}$ \\
\hline \multicolumn{3}{|c|}{ Pelton Turbine } \\
\hline $\boldsymbol{R}_{t}$ & Radios & $0,182 \mathrm{~m}$ \\
\hline $\boldsymbol{\theta}$ & Waterjet output angle & $60^{\circ}$ \\
\hline \multicolumn{3}{|c|}{ Hydropneumatic Storage System } \\
\hline$A_{o}$ & Accumulator piston area & $2 \mathrm{~m}^{2}$ \\
\hline$A_{1}$ & Hydraulic pump section area & $0,5 \mathrm{~m}^{2}$ \\
\hline$G$ & Gravity acceleration & $9,81 \mathrm{~m} / \mathrm{s}^{2}$ \\
\hline$P_{o}$ & Initial pressure & $1,5 \mathrm{MN} / \mathrm{m}^{2}$ \\
\hline$P_{2}$ & Atmospheric pressure & $0,1 \mathrm{MN} / \mathrm{m}^{2}$ \\
\hline$V_{L o}$ & Hyperbaric chambre volume & $5 \mathrm{~m}^{3}$ \\
\hline$P$ & $\mathrm{H}_{2} \mathrm{O}$ Specific mass & $1025 \mathrm{~kg} / \mathrm{m}^{3}$ \\
\hline \multicolumn{3}{|c|}{ Generator (DFIG) } \\
\hline$S_{n}$ & Apparent power (base) & $250 \mathrm{kVA}$ \\
\hline$V_{n}$ & Nominal voltage (base) & $380 \mathrm{~V}$ \\
\hline$I_{n}$ & Nominal Current & $189,9 \mathrm{~A}$ \\
\hline$P$ & Poles pairs & 2 \\
\hline$H_{r}$ & Inertia constant & $0,75 \mathrm{~s}$ \\
\hline $\boldsymbol{R}_{s}$ & Stator resistance & $0,0054 \mathrm{pu}$ \\
\hline $\boldsymbol{R}_{r}$ & Rotor resistance & $0,0060 \mathrm{pu}$ \\
\hline$L_{L s}$ & Stator leakage inductance & $0,1 \mathrm{pu}$ \\
\hline$L_{L r}$ & Rotor leakage inductance & $0,11 \mathrm{pu}$ \\
\hline$L_{m}$ & Magnetizing inductance & $4.5 \mathrm{pu}$ \\
\hline
\end{tabular}

A real sea state with significant wave height $\left(H_{s}\right)$ of $1 \mathrm{~m}$ and an average period $\left(T_{a v}\right)$ of 6 seconds is considered. The total simulation time is 400 seconds.

The water flow rates of each float-pump module and total water flow is shown in Fig. 8. Naturally the total average water flow is increased with the increasing of pumping modules number connected to the common HSS. However, a critical issue in large wave generation farms is the superposition of water flow peaks of individual pumping modules. Thus, these generating farms should be equipped with mechanical protection systems, interlocks and pressure relief valves.

Fig. 9 shows the IMP position profile $\delta$ and the water flows $Q_{\text {in }}$ and $Q_{\text {out }}$ during a change from 0 to $0,4 \mathrm{~m}$ in $\delta_{\text {ref }}$. The change in the $\delta_{\text {ref }}$ starts at 150 seconds and increases ramped up to 230 seconds (inclination of $0.5 \%$ ). The IMP position follows the reference keeping fluctuations $(\Delta \delta)$ around the average reference value, $\delta_{\text {ref }}$. The $I M P$ fluctuations, $\Delta \delta$, characterize the filtering of the oscillating wave power. The "power leveling" is clearly seen when we compare the input and output water flow profiles $\left(Q_{\text {in }}\right.$ and $\left.Q_{\text {out }}\right)$. 

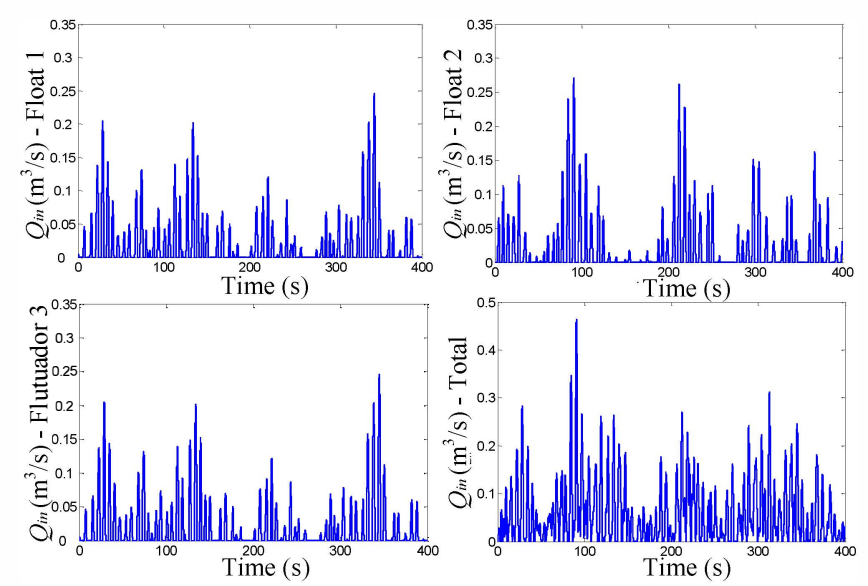

Fig. 8. HSS water flows.
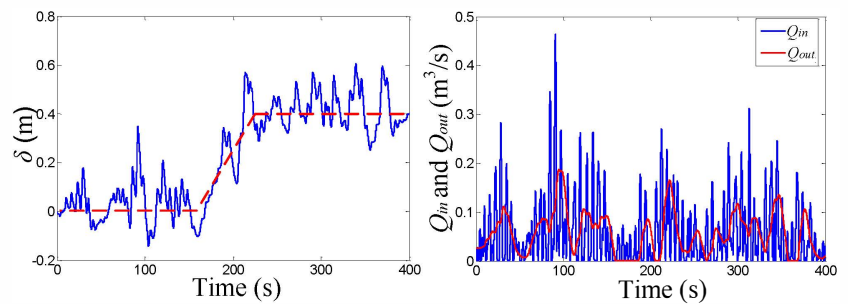

Fig. 9. HSS piton position and water flows.

The HSS pressure $P_{1}$ and the waterjet speed $V_{2}$ are shown in Fig. 10. The average levels of $P_{1}$ and $V_{2}$ vary proportionally with the average position reference $\delta_{\text {ref }}$ and the fluctuations around the average values are also present, characterizing the wave power filtering. Thus, the IMP position control loop can be used to indirectly control the HSS pressure $P_{l}$, and consequently the waterjet speed $V_{2}$. The control of HSS pressure is essential to keeping the floating bodies operating at maximum efficiency in any sea state, i.e. in resonance with the incident wave. Note that the HSS pressure variation range can be expected in the structural design of the HSS, experiencing maximum $\left(\delta_{\max }\right)$ and minimum $\left(\delta_{\min }\right)$ values. For example, in this work it was considered that starting from the initial position, the $H S S$ internal piston can move freely $0,5 \mathrm{~m}$ up or down $(\Delta \delta= \pm 0,5 \mathrm{~m})$. Using (14) the $P_{l}$ variation range is from $1,25 \mathrm{MN} / \mathrm{m}^{2}$ to $1,87 \mathrm{MN} / \mathrm{m}^{2}$. Obviously, the range of operating hydraulic pressures will depend on the characteristic of the site (characteristics sea state). So the structural design of the HSS should be implemented after a careful study of the wave climate of the site.
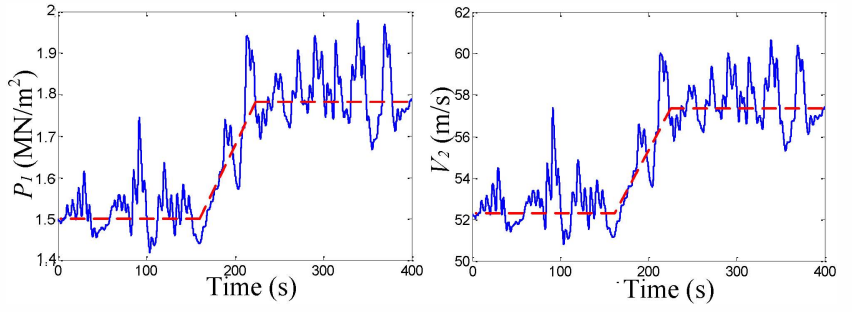

Fig. 10. HSS pressure and waterjet speed - Case 1.

The water jet area $A_{2}$ and the errors $\left(\varepsilon\right.$ and $\varepsilon_{\text {filt }}$ ) are presented in Fig. 11. In some moments $A_{2}$ is set to the minimum level (limiter in the output of the $P I$ controller). In these moments the water flow $Q_{\text {in }}$ reaches very small values. To keep $\delta$ near the reference $\delta_{\text {ref }}, A_{2}$ area falls to a minimum level $\left(0,01 \mathrm{~cm}^{2}\right)$, substantially "closed" the HSS. As expected, the error $\varepsilon$ oscillates around the value zero.
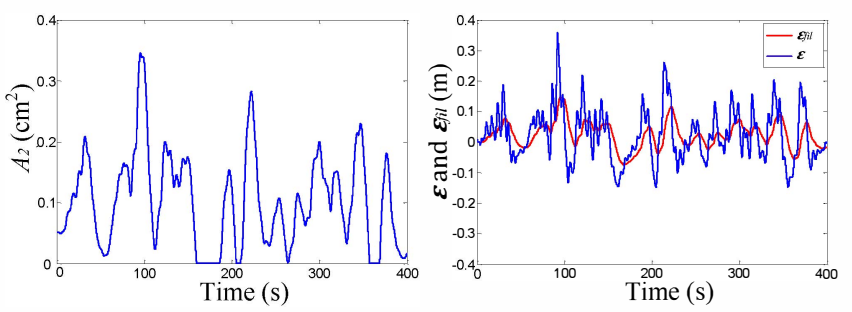

Fig. 11. Waterjet area and positions errors.

As seen in Fig. 12, the mechanical power $\left(P_{m}\right)$ and generated power $\left(P_{G}\right)$ are very similar. It is observed that in lower energy sea states $P_{m}$ and $P_{G}$ become null. A similar forms of powers $P_{m}$ and $P_{G}$ show that there is no power filtering when the speed control is applied to $D F I G$ and all mechanical power intermittence are transferred to the electrical grid.
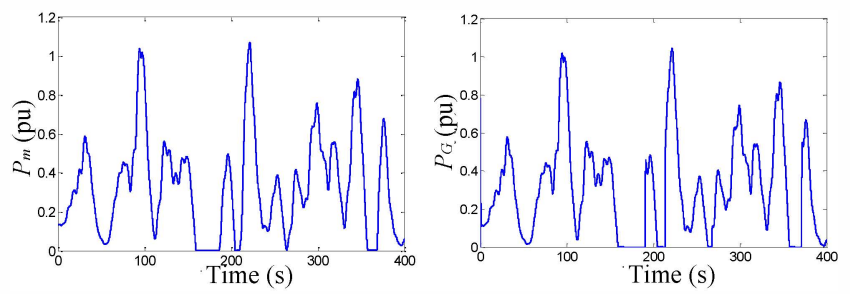

Fig. 12. Mechanical and generated powers.

Fig. 13 shows that $\omega_{m}$ speed follows the $\omega_{\text {ref }}$ reference, with the exception of lower wave energy periods. At this time the input water flow $Q_{i n}$ is next to zero (between 150 and 200 and between 350 and 380 seconds). In these ranges, the area $A_{2}$ is substantially zero and the mechanical power in the turbine approaches of zero. Consequently, the turbine speed must fall. When a significant input water volume is again pumped to the $H S S$, the $A_{2}$ area and $Q_{o u t}$ water flow return to be increased and the turbine is again accelerated due to the waterjet action. The $P C C$ voltage is also seen in Fig. 13. The observed profile is due to the intermittent generated power $P_{G}$.

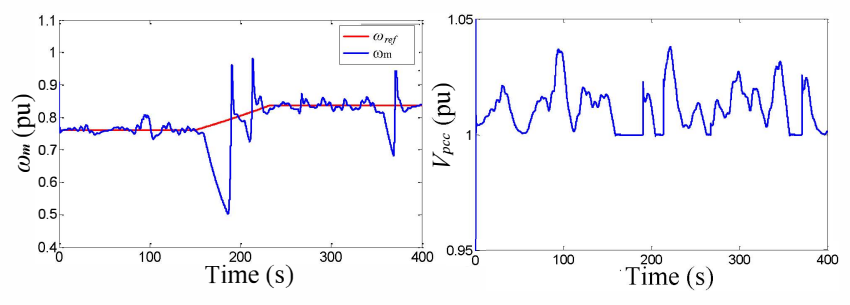

Fig. 13. Mechanical speed and $P C C$ voltage.

\section{CONCLUiONS}

This paper presented a complete modeling of a WEC developed by COPPE / UFRJ researches. The integrated HSS and DFIG control strategies were proposed and discussed. Control of IMP position allowed an indirect adjustment of hydraulic pressure $P_{l}$ which is fundamental to operate the floating bodies at maximum efficiency. Associated with the $I M P$ position control have been proposed the DFIG speed 
control. It was observed that all the mechanical power from the turbine was reflected to the grid in the form of abrupt $P C C$ voltage variations. However, all the wave energy extracted is transferred to hydraulic turbine that always works at maximum efficiency.

The observation of the IMP position control loop also helped to dictate rules on possible hydraulic pressure adjustment ranges according to the structural design of the HSS. In this sense, the implementation of smaller hyperbaric chamber volumes $V_{L O}$ allow greater hydraulic pressure setting range. However a lower HSS power filtering levels will be observed. In addition, a larger hydraulic pressure adjustment range $P_{1}$ will also lead to a greater range of waterjet speeds $V_{2}$ and consequently $\omega_{\text {ref }}$ (see Eq. (22)). Therefore, the rated power of the back-to-back converter required will also be increased.

In a dual way, larger chamber volumes $V_{L O}$ provides a greater wave power filtering levels and a lower hydraulic pressure setting range. Consequently, the waterjet speed range and the back-to-back nominal power will be lower.

\section{ACKNOWLEDGMENT}

This work was partially supported by FAPERJ - Cientista do Nosso Estado Proc. No. E-26/102.974/2011 as well as by CNPq (Bolsa PQ) Proc. No. 305114/2009-3. The authors also thank Tractebel Energia for technical and financial support.

\section{REFERENCES}

[1] POLINDER, H.; SCUOTTO, M.; "Wave Energy Converters and Their Impact on Power Systems", In: International Conference on Future Power Systems, pp 1-9,Nov.2005.

[2] MOLINAS, M., SKJERVHEIM, O., ANDREASEN, P., UNDELAND, T., HALS, J., MOAN, T., 2007, "Power Eletronics as Grid Interface for Actively Controlled Wave Energy Converters", In: International Conference on Clean Electrical Power (ICCEP).

[3] HANSEN, R.H., ANDERSEN, T.O., PERDERSEN, H.C., 2011, "Analysis of Discrete Pressure level Systems for Wave Energy Converters", In: Conference on Fluid Power and Mechatronics (FPM).

[4] KIPRAKIS, A.E., NAMBIAR, A.J., FOREHAND, D.I.M., WALLACE, A.R., 2009, "Modelling Arrays of Wave Energy Converters connected to Weak Rural Electricity Networks", In: Internetional Conference on Sustainable Power Generation and Supply (SUPERGEN).

[5] GARCES, A., TEDESCHI, E., VEREZ, G., MOLINAS, M., 2010, "Power Collection Array for Improved Wave Farm Output Based on Reduced Matrix Converters", In: Workshop on Control anda Modelling for Power Electronics (COMPEL)

[6] GARCIA-ROSA, P.B., 2008, "Controle e Otimização de um Sistema de Conversão de Energia das Ondas do Mar em Energia Elétrica", Dissertação de Mestrado, Programa de Engenharia Elétrica, COPPE/UFRJ.

[7] GARCIA-ROSA, P.B., MACHADO, I.R., CUNHA, J.P.V.S., LIZARRALDE, F., WATANABE, E.H., ESTEFEN, S.F., 2010, "Modelagem Dinâmica de um Conversor Hiperbárico de Energia das
Ondas em Energia Elétrica", Em: XVII Congresso Brasileiro de Automática (CBA), Bonito - MS

[8] GARCIA-ROSA, P. B. ; LIZARRALDE, F. ; CUNHA, J. P. V. S. ; ESTEFEN, S. F. ; MACHADO, I. R. ; WATANABE, E.H. . Wave-toWire Model and Energy Storage Analysis of an Ocean Wave Energy Hyperbaric Converter. IEEE Journal of Oceanic Engineering, p. 1-12, 2013.

[9] MACHADO, I. R. ; Bozzi, F. A. ; Watanabe, E. H. . Análise da Influência dos Sistemas de Armazenamento de Energia na Geração a Partir de Ondas. In: XXI Simpósio Nacional de Produção e Transmissão de Energia Elétrica, 2011, Florianópolis.

[10] MARTINEZ, M. ; MOLINA, M. G. ; MACHADO, I. R. ; MERCADO, P. E. ; Watanabe, E. H. . Modelado y Simulación de un Conversor de Energía Hiperbárico de Olas Oceánicas Para Aplicaciones en Generación Distribuida. In: HIDRÓGENO Y FUENTES SUSTENTABLES DE ENERGíA - HYFUSEN, 2011, Mar del Plata Argentina. Fuentes Renovables de Energía, 2011.

[11] MARTINEZ, M.; MOLINA, M.G. ; MACHADO, I. R. ; Mercado, P.E. ; Watanabe, E.H. . Modelling and simulation of wave energy hyperbaric converter (WEHC) for applications in distributed generation. International Journal of Hydrogen Energy, v. 1, p. 1-6, 2012.

[12] GARCIA-ROSA, P.B., 2013, "Modelagem Dinâmica e otimização de Sistemas de Conversão de Energia das Ondas em Energia Elétrica", Tese de Doutorado, Programa de Engenharia Elétrica, COPPE/UFRJ.

[13] MACHADO, I.R., 2013, "Geração Elétrica a Partir de Ondas do Mar Modelo Completo e Análie do Sitema de Armazenamento de Energia ", Tese de Doutorado, Programa de Engenharia Elétrica, COPPE/UFRJ.

[14] FALNES, J. (2002), "Ocean Waves and Oscillanting Systems Linear Interaction Including Wave-Energy, Cambridge University Press, USA.

[15] PARSONS, W. \& BADDOUR, R. E., 2004, "The generation and propagation of deep water multichromatic nonlinear long-crested surface waves", In: Proceedings of the Fourteenth International Offshore and Polar EngineeringConference, pp. 249-245.

[16] GREENHOW, M. \& WHITE, S. P. (1997), 'Optimal heave motion of some axisymmetric wave energy devices in sinusoidal waves',Applied Ocean Research19(3), 141-159.

[17] CUMMIS, W. E. (1962), The impulse response function and shipmotions, in 'Schiffste-chnik', Vol. 47, pp. 101-109.

[18] LIVI, C. P, 2004, “ Fundamentos de Fenômenos de Transporte". Capítulo 5, Livros Técnicos e Científicos Editora S.A.

[19] BOSE, B. K., "Modern Power Eletronics And AC Drives", Prentice Hall PTR, 2002.

[20] KRAUSE, P., WASYNCZUK, O., SUDHOFF, S., 2002, Analysis of Electric Machinery and Drive Systems. 2a ed. New York: Wiley-IEEE Press.

[21] LIMA, F. K. A., 2009, “Aerogerador Baseado em Máquina de Indução Duplamente Alimentada - Suportabilidade para Afundamento de Tensão", Tese de Doutorado, Programa de Engenharia Elétrica, COPPE/UFRJ.

[22] LIMA, F.K.A.; WATANABE, E.H., "Parallel Connection of DoublyFed Induction Generator in Wind Generation", in 9o Congresso Brasileiro de Eletrônica de Potência, vol. 9, pp. 631-639, 2007.

[23] LEONHARD, W., 2001, "Control of Electrical Drives", 3 a. ed. New York: Springer. 